Journal of Engineering and Applied Sciences 15 (7): 1626-1634, 2020

ISSN: 1816-949X

(C) Medwell Journals, 2020

\title{
Electrical Modeling of the Induced Voltage Test in Power Transformers for the Analysis of Frequency Response
}

\author{
${ }^{1}$ Juan David Rivera Niquepa, ${ }^{2} J u a n$ Carlos Castro Galeano, \\ ${ }^{3}$ German Andrés Gutiérrez Patiño and ${ }^{4}$ Ivan David Alfonso \\ ${ }^{1}$ Electromechanical Engineering, Researcher GridsE UPTC Duitama, Colombia \\ ${ }^{2}$ Electromechanical Engineering, Director GridsE UPTC, Duitama, Colombia \\ ${ }^{3}$ Electronic Engineering, Researcher DSP-UPTC, Sogamoso, Colombia \\ ${ }^{4}$ Department of Software Engineering, Researcher TICS w-Uniandes, Bogotá, Colombia
}

\begin{abstract}
The structure of the induced voltage test model for low frequency transients is described and presented from its components (generator, auxiliary and power transformer). The performed test procedures are perfomed to estimate the model parameters along with the topology of their connection. Finally, the model is implemented in the transient analysis software ATP and a frequency response of the test is obtained. This allows to identify the critical frequencies that cause resonant states and cause overvoltage during the test which facilitates the establishment of application of safety criteria for both operators and the equipment.
\end{abstract}

Key words: ATPDraw, resonance, induced voltage, power transformer, frequency

\section{INTRODUCTION}

The induced voltage test is a routine procedure done in power transformers after being build, intervened or repowered and before placing them in substations for their operation (Hernández et al., 2007). The test is performed to evaluate the rigidity of the insulation between turns. This insulation in most cases is made of Kraft paper impregnated with dielectric oil that overcoats the conductors of high and low voltage coils (Sylvain et al., 2015). The procedure consists of inducing a potential in the high voltage winding at a specific value. This induced voltage is close to the double the nominal voltage of the equipment in accordance with the established levels in the international standard IEEE and IEC associated with the test: IEEE Std C57.12.00-2010, IEEE Std C57.12.902006, IEC 60.076-3 de 2000.

To make the voltage induction effective in the high voltage winding, the frequency and the test time is adjusted. Generally, the induction frequency is doubled to avoid saturation in the ferromagnetic core (Mohseni et al., 2008, McDermid, 2016) and the test is executed for one minute. The time and frequency parameters can be adjusted as long as 7200 cycles of the sinusoidal wave are guaranteed. The test conditions require speed variation in the generator, such frequency variation eventually presents the phenomenon of resonance during the test which represents a risk for the measuring equipment, the operators and the transformer. The general circuit of induced voltage test is shown in Fig. 1:

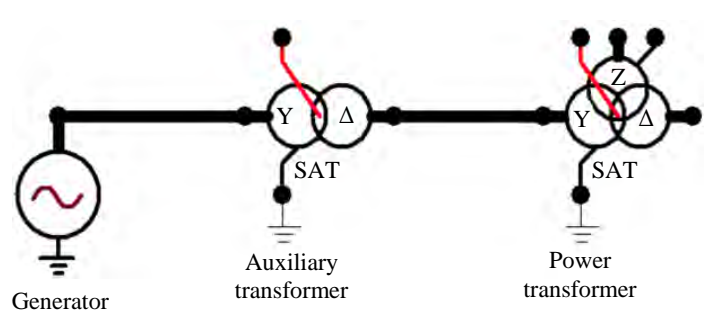

Fig. 1: Circuit-induced voltage test

To identify the resonance frequencies, a RLC model is built from the principal elements shown in Fig. 1. The estimation of the electric parameters of both the generator and the transformers is made by laboratory testing without including the internal characteristics of the machine such as the geometry of the core and caliber of the conductors, among others. This is with the purpose of not requiring or not having the information that in the majority of cases only the equipment manufacturer has.

The modeling of the test is focused on the transformers which together can present phenomena such as resonance, ferro resonance and transient commutation during the voltage energization and induction (MartinezVelasco, 2009). Proper modeling of these low frequency phenomena (from the order of $\mathrm{Hz}$ to a few $\mathrm{kHz}$ ) requires including the parameters of the core, magnetization, hysteresis, saturation, frequency dependence of dispersion inductances and capacitive couplings of the machines (Martinez-Velasco, 2009). For the transformers, as a starting point, the hybrid model for the simulation of low frequency transients is taken. This model originates from

Corresponding Author: Juan David Rivera Niquepa, Electromechanical Engineering, Researcher GridsE UPTC Duitama, Colombia, E-mail: juandavid.rivera@uptc.edu.co, Tel.:+57-316 8790853 
the analogy between a magnetic circuit and an electric circuit which allows a precise simulation of transients up to $5 \mathrm{kHz}$ (Mork et al., 2006a, b).

The induced voltage test consists of energizing the power transformer in a vacuum at a frequency different from the nominal one, the frequency variation modifies its inductive and capacitive reactances up to the point of canceling each other and originating a state of resonance. This phenomenon manifests itself with significant elevations in voltage in short times which represents a risk for operators, sensitive measurement equipment and the power transformer as well. For this reason, it is convenient to estimate the resonance frequencies and from this, to take preventive measures to mitigate the risks. In this sense, a test model is proposed for low frequency transients (Martinez and Mork, 2005). Furthermore, the frequency response is obtained and analyzed for a specific case.

The methodology of testing and modeling of each element of the test, the mathematical structure of the model, and the simulation is presented. Section 3 evaluates the results obtained in the frequency response curves. Finally, general conclusions drawn from the research are presented.

\section{MATERIALS AND METHODS}

To consolidate the test model, the modeling of each of the elements that composes it, together with the procedures carried out for the estimation of the RLC parameters is proposed.

Generator model: The generator is a highly complex machine in its modeling because it must include both electrical and mechanical behavior and the operating regime. For this reason, a simplified representation is used which implies the state operation in direct axis considering the saturation and ground capacitance of the armature (Martinez-Velasco, 2009). In many cases, the generator modeling includes field winding together with the control system to evaluate time domain performance (Barakat et al., 2011). However, to calculate the frequency response, the synchronous generator inductance, stable armature ground capacitances and the balanced operation of the generator are particularly important (Barakat et al., 2011, Despalatovic et al., 2011, Hadi and Wijaya, 2013). Figure 2 shows the circuit corresponding to the modeling of the generator:

The model consists of an AC source, the armature resistance, the synchronous reactance and the armature capacitance. The set of parameters brings together phenomena such as: losses in copper, self and mutual induction, armature reaction and grounding insulation (Barakat et al., 2011).

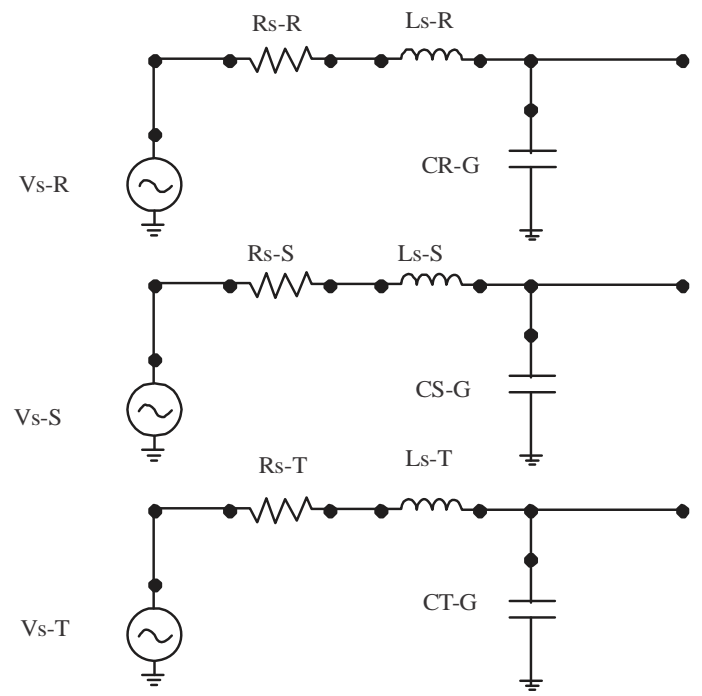

Fig. 2: Generator model

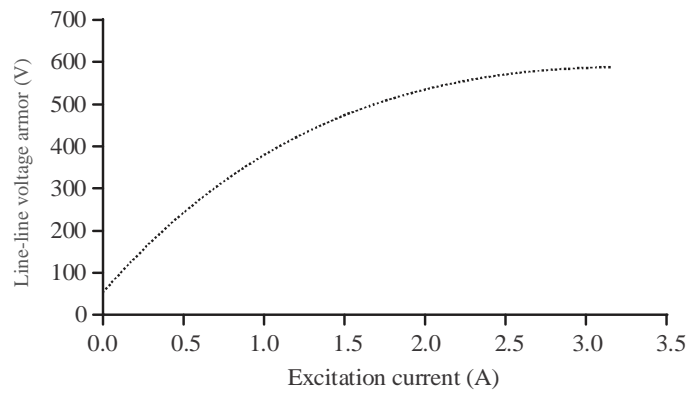

Fig. 3: Off-load characteristic of the generator

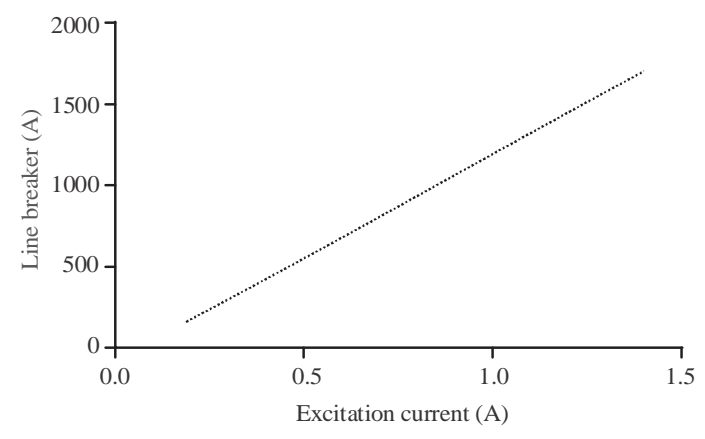

Fig. 4: Short-circuit characteristic of the generator

Electrical generator tests: For the estimation of the generator parameters, the vacuum and short-circuit tests were performed according to the guidelines established by IEEE (Coultes and Waston, 1981; IEEE., 2009). Such tests allow for the estimation of the synchronous reactance considering the saturation. The results obtained for the vacuum test as a function of the excitation current are shown in Fig. 3:

The short-circuit characteristic of the generator as a function of the excitation current is shown in Fig. 4: 


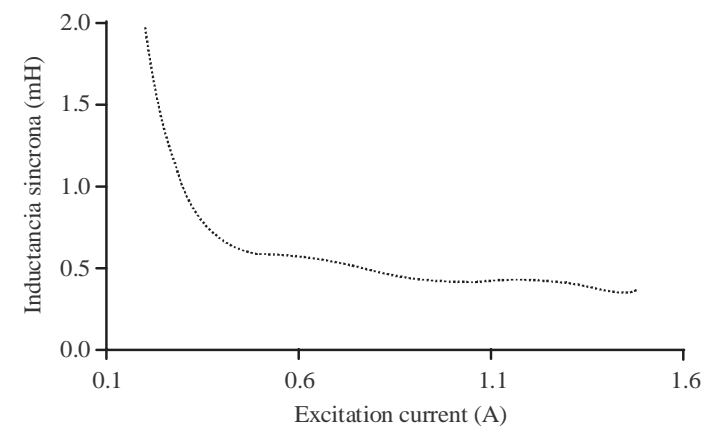

Fig. 5: Synchronous inductance of the generator

The synchronous inductance of the generator from its own characteristics is obtained using Eq. 1:

$$
\mathrm{L}_{\mathrm{s}}=\frac{\mathrm{V}_{\mathrm{OC}}}{2 \pi \mathrm{fI}_{\mathrm{CC}}}(\mathrm{H})
$$

where $\mathrm{V}_{\mathrm{OC}}$ and $\mathrm{I}_{\mathrm{CC}}$ are the vacuum Voltage (V) and the short-circuit current (A) for a given excitation current, respectively; $\mathrm{f}$ is the frequency of the system (IEEE., 2009). The behavior of the synchronous inductance for a given excitation regime referred to $120 \mathrm{~Hz}$ is presented in Fig. 5:

It is observed that with low excitation there is high inductance but as the excitation increases to nominal values, the dispersion is reduced and the synchronous inductance decreases. The resistance per phase is estimated by the DC value measured with the machine without movement and the capacitances are obtained by the insulation resistance test executed with the M4000 equipment. In this way, a complete characterization of the generator parameters is obtained.

Transformer model: The induced voltage test circuit includes two transformers: auxiliary and power. The first one raises the output voltage of the generator to required levels whereas the second one is the element under test subjected to an overvoltage for one minute depending on the test frequency. The modeling topology is considered separately for each transformer because the capabilities are different. In the case of the auxiliary transformer, this is of the order of hundreds of $\mathrm{kVA}$ whereas the transformer under test is of powers of up to one hundred MVA which requires considerations such as dispersion, magnetization and core losses (Martinez-Velasco, 2009). However, both circuits start from the hybrid model.

The hybrid model is developed for analysis of medium and low frequency transients. This incorporates phenomena such as dispersion, saturation, iron losses, hysteresis and capacitive couplings (Morket al., 2006a, b). The structure of this model is deduced from the magnetic circuit which represents the windings as electromotive forces and the core as reluctances which by analogy, allow to obtain the RLC electrical circuit that allows to perform frequency response analysis (Mitchell and OOliverira, 2012; Kaniewski, 2011).

Auxilliary transformer parameters: The model of the three-column auxiliary transformer is based on the proposal by Celis et al. Capacitive couplings are added ground-line and between windings which gives place to the circuit shown in Fig. 6:

The hybrid model of the three-phase transformer of three-columns for low-frequency transients used for the auxiliary transformer is based on the magnetic circuit developed in Moses et al. (2010) which by electromagnetic analogy, allows to define the RLC components of the circuit. As shown in Fig. 6, copper losses in the primary are represented by $R_{p-A}, R_{p-B}$ and $R_{p-C}$ and for the secondary as $\mathrm{R}_{\mathrm{s}-\mathrm{A}}, \mathrm{R}_{\mathrm{s}-\mathrm{B}}$ and $\mathrm{R}_{\mathrm{s}-\mathrm{C}}$. Moreover, the dispersion phenomenon in the primary is represented by $\mathrm{L}_{\mathrm{p}-\mathrm{A}}, \mathrm{L}_{\mathrm{p}-\mathrm{B}}$ and $\mathrm{L}_{\mathrm{p}-\mathrm{C}}$ and for the secondary as $\mathrm{L}_{\mathrm{s}-\mathrm{A}}, \mathrm{L}_{\mathrm{s}-\mathrm{B}}$ and $\mathrm{L}_{\mathrm{s}-\mathrm{C}}$; these resistive and inductive elements represent the transformer windings. For the case of the core, $R_{m}$ and $L_{m}$ are included which represent the losses in the iron and the magnetization of the core for each phase of the transformer, respectively. Ideal transformers are incorporated in the input and output to make effective the voltage elevation characteristic of the transformer. Zero sequence phenomena are added by induction of homopolar sequence $\mathrm{L}_{\mathrm{h}}$. Additionally, capacitive couplings are incorporated for each of the phases between the windings and ground and between primary and secondary $\mathrm{C}_{\mathrm{L}}, \mathrm{C}_{\mathrm{H}}$ and $\mathrm{C}_{\mathrm{HL}}$, respectively.

Power transformerparameters: The model developed for the power transformer is based on the proposal by Martinez-Velasco (2009), Mork et al. (2006a, b), Moses et al., 2010). Because of geometry effects and significantly greater capacity, this model differs from the previous model. This results in the separation of the core of the windings forming a different topology (Morket al., 2006a, b) which is shown in Fig. 7:

For the power transformer, the parameters that compose it correspond to: Resistances of ohmic losses in the copper for both primary and secondary, $R_{L}$ and $R_{H}$, respectively for each of the phases; total inductance of core dispersion per phase $\mathrm{L}_{\mathrm{sh}}$; resistance losses in the iron $R_{M}$ and magnetization inductance $L_{M}$ for each of the phases; homopolar sequence inductance $L_{h}$; capacitive couplings between phases and ground on high and low voltage side $\mathrm{C}_{\mathrm{H}}$ and $\mathrm{C}_{\mathrm{L}}$, respectively and capacitive couplings between $\mathrm{C}_{\mathrm{HL}}$ windings (Herrera et al., 2013).

Transformer electrical testing: The parameter estimation of the proposed low frequency models for transformers is based on routine and specialized tests together with the characteristicquantities of the transformer. The necessary tests for the estimation of parameters are: 


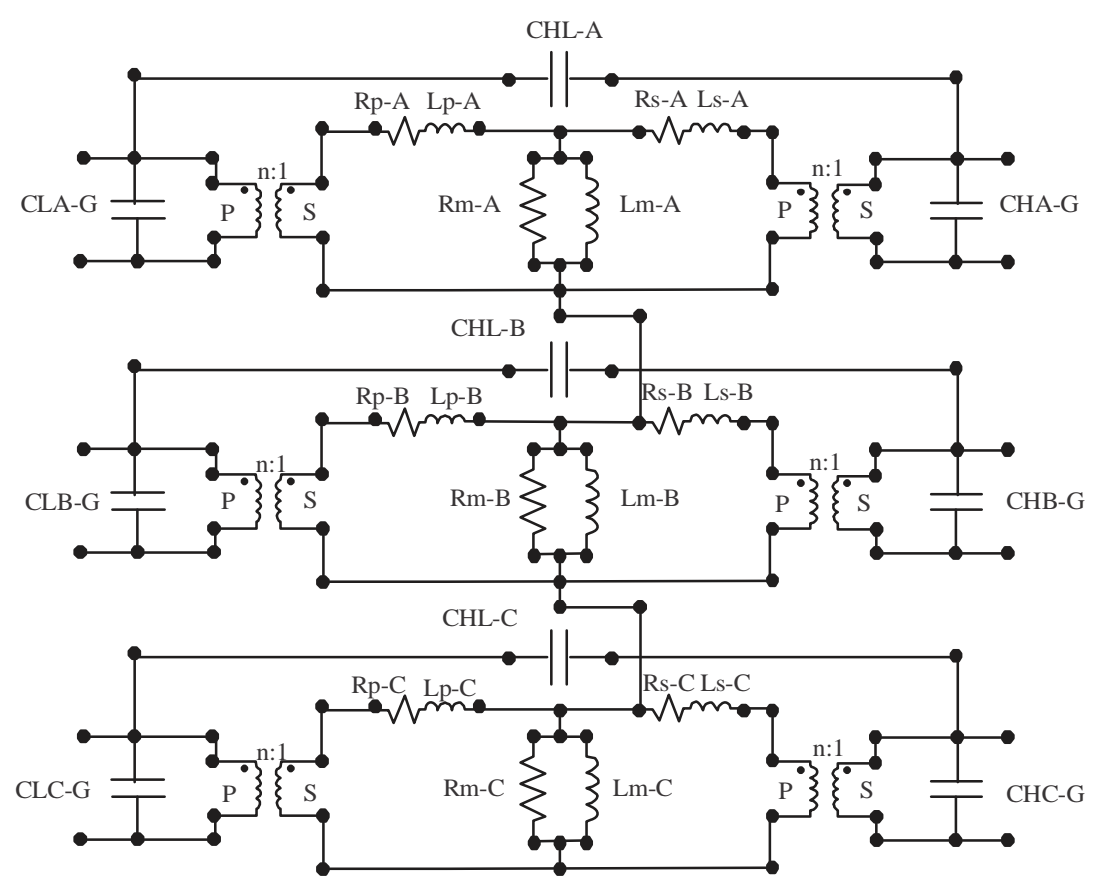

Fig. 6: Auxiliary transformer model

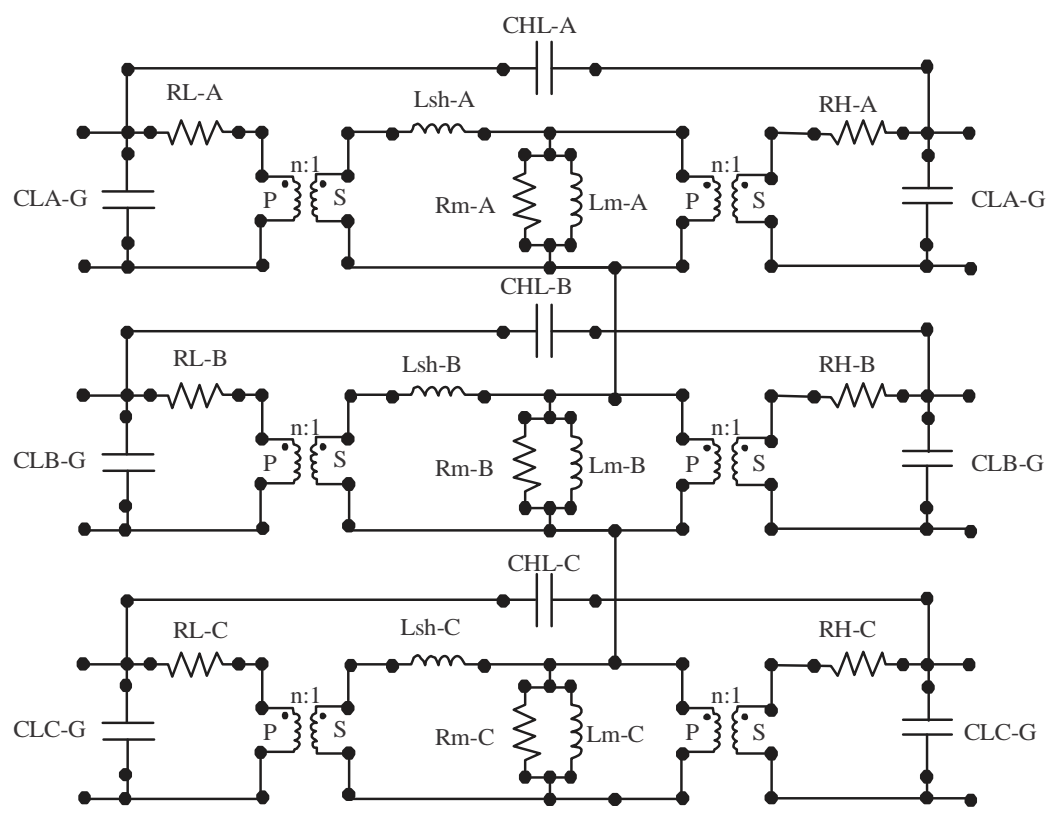

Fig. 7: Power transformer model

- Short-circuit test and losses with load

- Excitation test and empty losses

- Measurement of insulation capacitances

The description of protocols and test procedures are specified in detail in the standards: IEEE Std C57.12.002010, IEEE Std C57.12.90-2006 (IEEE,. 2010).
Estimation of auxiliary transformer parameters: From the obtained results of the tests performed, the parameters of the auxiliary transformer model shown in Fig. 6 are obtained. Before the estimation, the following input data are established: 
Primary configuration constant: Considering the connection of the primary winding, the primary configuration constant is obtained by Eq. 2:

$$
\mathrm{k}_{\mathrm{C}}=\left\{\begin{array}{l}
3, \text { for } \Delta \text { conection } \\
1, \text { for } \mathrm{Y} \text { conection }
\end{array}\right.
$$

Short-circuit resistance: The short-circuit resistance is calculated by Eq. 3:

$$
\mathrm{R}_{\mathrm{cc}}=\mathrm{P}_{\mathrm{cc}} *\left[\frac{\mathrm{V}_{\mathrm{LL}-\mathrm{prim}}}{\mathrm{S}_{\mathrm{nom}}}\right]^{2}
$$

Where:

$\mathrm{P}_{\mathrm{cc}} \quad$ : Short-circuit power (W)

$\mathrm{V}_{\text {LL-prim }}$ : Line-to-line voltage of the primary(V)

$\mathrm{S}_{\text {nom }}$ : Apparent power (VA)

Nominal transformation ratio: The nominal transformation ratio is obtained by Eq. 4:

$$
\mathrm{n}_{\text {nom }}=\frac{\mathrm{V}_{\mathrm{LL}-\text { prim }}}{\mathrm{V}_{\mathrm{LL}-\mathrm{sec}}}
$$

Effective transformation ratio: The effective transformation ratio is calculated by means of Eq. 5 according to the connection configuration of the transformer:

$$
\mathrm{n}_{\mathrm{ef}}= \begin{cases}\sqrt{3} * \mathrm{n}_{\mathrm{nom}}, & \text { for } \Delta Y \text { configuration } \\ \frac{1}{\sqrt{3}} * \mathrm{n}_{\mathrm{nom}}, & \text { for } \mathrm{Y} \Delta \text { configuration }\end{cases}
$$

Short-circuit admittance: The short-circuit admittance is obtained by Eq. 6:

$$
\mathrm{X}_{\mathrm{cc}}=\left[\frac{\mathrm{V}_{\mathrm{LL}-\mathrm{prim}}}{\mathrm{S}_{\mathrm{nom}}}\right]^{2} * \sqrt{\left(\frac{\mathrm{Z}_{\mathrm{cc}} \mathrm{S}_{\mathrm{nom}}}{100}\right)^{2}-\mathrm{P}_{\mathrm{cc}}{ }^{2}}
$$

Where:

$\mathrm{Z}_{\mathrm{cc}}$ : Board short-circuit impedance (\%)

From these input data, the model parameters are estimated from the following mathematical models:

Copper loss resistance in the primary: The copper loss resistance in the primary is obtained from the preliminary data and DC resistances of the primary (Rprim) and secondary (Rsec) windings and is calculated for each of the phases a, b and c according to Eq. 7:

$$
\mathrm{R}_{\mathrm{p}-\mathrm{a}}=\frac{\mathrm{k}_{\mathrm{C}}}{4}\left[2 \mathrm{R}_{\mathrm{CC}}+\mathrm{R}_{\mathrm{prim}}-\mathrm{R}_{\mathrm{sec}} \mathrm{n}_{\mathrm{ef}}^{2}\right]=\mathrm{R}_{\mathrm{p}-\mathrm{b}}=\mathrm{R}_{\mathrm{p}-\mathrm{c}}
$$

Copper loss resistance in the secondary: The copper loss resistance in the secondary is obtained from the preliminary data and is calculated for each phase by Eq. 8 referred to the primary winding:

$$
\mathrm{R}_{\mathrm{s}-\mathrm{a}}=\frac{\mathrm{k}_{\mathrm{C}}}{4}\left[2 \mathrm{R}_{\mathrm{CC}}-\mathrm{R}_{\text {prim }}+\mathrm{R}_{\mathrm{sec}} \mathrm{n}_{\text {ef }}^{2}\right]=\mathrm{R}_{\mathrm{s}-\mathrm{b}}=\mathrm{R}_{\mathrm{s}-\mathrm{c}}
$$

Dispersion inductances: The dispersion inductances are obtained for each of the phases in both the primary and secondary winding by Eq. 9:

$$
\mathrm{L}_{\mathrm{p}-\mathrm{a}}=\frac{\mathrm{k}_{\mathrm{C}}}{2}\left[\frac{\mathrm{X}_{\mathrm{CC}}}{2 \pi \mathrm{f}}\right]=\mathrm{L}_{\mathrm{p}-\mathrm{b}}=\mathrm{L}_{\mathrm{p}-\mathrm{c}}=\mathrm{L}_{\mathrm{s}-\mathrm{a}}=\mathrm{L}_{\mathrm{s}-\mathrm{b}}=\mathrm{L}_{\mathrm{s}-\mathrm{c}}
$$

Iron loss resistance: The iron loss resistance is obtained for each phase by Eq. 10-12:

$$
\begin{aligned}
& \mathrm{R}_{\mathrm{m}-\mathrm{a}}=\frac{\mathrm{K}_{\mathrm{C}}}{3} * \frac{\left(\mathrm{V}_{\text {prim }}\right)^{2}}{\mathrm{P}_{0-\mathrm{a}}} \\
& \mathrm{R}_{\mathrm{m}-\mathrm{b}}=\frac{\mathrm{K}_{\mathrm{C}}}{3} * \frac{\left(\mathrm{V}_{\text {prim }}\right)^{2}}{\mathrm{P}_{0-\mathrm{b}}} \\
& \mathrm{R}_{\mathrm{m}-\mathrm{a}}=\frac{\mathrm{K}_{\mathrm{C}}}{3} * \frac{\left(\mathrm{V}_{\text {prim }}\right)^{2}}{\mathrm{P}_{0-\mathrm{c}}}
\end{aligned}
$$

where $\mathrm{P}_{\mathrm{o}}$ are the losses in the core obtained in the vacuum test in each of the phases.It is necessary to clarify that the losses are smaller in the central column of the core because it handles a different flow than the lateral columns.

Core magnetization inductance: The core magnetization inductance is obtained by Eq. 13-15:

$$
\begin{aligned}
& \mathrm{L}_{\mathrm{m}-\mathrm{a}}=\frac{\mathrm{K}_{\mathrm{C}}}{3 * 2 \pi \mathrm{f}} * \frac{\left(\mathrm{V}_{\text {prim }}\right)^{2}}{\mathrm{Q}_{0-\mathrm{a}}} \\
& \mathrm{L}_{\mathrm{m}-\mathrm{b}}=\frac{\mathrm{K}_{\mathrm{C}}}{3 * 2 \pi \mathrm{f}} * \frac{\left(\mathrm{V}_{\text {prim }}\right)^{2}}{\mathrm{Q}_{0-\mathrm{b}}} \\
& \mathrm{L}_{\mathrm{m}-\mathrm{a}}=\frac{\mathrm{K}_{\mathrm{C}}}{3 * 2 \pi \mathrm{f}} * \frac{\left(\mathrm{V}_{\text {prim }}\right)^{2}}{\mathrm{Q}_{0-\mathrm{c}}}
\end{aligned}
$$

where $\mathrm{Q}_{0}$ corresponds to the reactive power of each phase which is obtained from Eq. 16:

$$
\mathrm{Q}_{0}=\sqrt{\left(\frac{\mathrm{V}_{\text {prim }} * \mathrm{I}_{\mathrm{of}}}{3}\right)^{2}-\mathrm{P}_{0 \mathrm{f}}{ }^{2}}
$$


where $I_{o f}$ and $P_{o f}$ are the vacuum currents and the vacuum losses of each of the phases, respectively. In this way, an estimated value of the parameters that compose the model is available.

Power transformer parameter estimation: Because the capacity and geometry of the power transformer are significantly greater than the auxiliary one, in this case a different mathematical treatment is taken as reference. Again, from the results of the tests of the transformer, the parameters that are part of the model of Fig. 7 are estimated.

Transformation ratio: The transformation ratio is obtained by Eq. 17 similar to the previous case:

$$
\mathrm{n}=\frac{\mathrm{N}_{\mathrm{L}}}{\mathrm{N}_{\mathrm{H}}}=\frac{\mathrm{V}_{\mathrm{L}}}{\mathrm{V}_{\mathrm{H}}}
$$

Where:

$\mathrm{V}_{\mathrm{L}}$ : Line-to-line voltage of the primary

$\mathrm{V}_{\mathrm{H}}$ : Line-to-line voltage of the secondary

Configuration constant of the primary: The primary configuration constant is obtained by Eq. 18:

$$
\mathrm{K}= \begin{cases}3, & \text { for } \Delta \text { connection } \\ 1, & \text { for } \mathrm{Y} \text { connection }\end{cases}
$$

Copper loss resistance in the primary: The copper loss resistance in the primary is obtained from the results of the short-circuit test and are given by Eq. 19:

$$
\mathrm{R}_{\mathrm{L}-\mathrm{A}}=\frac{\mathrm{K} *(1-\alpha)}{3} * \frac{\mathrm{P}_{\mathrm{CC}}}{\left(\mathrm{I}_{\mathrm{CC}}\right)^{2}}=\mathrm{R}_{\mathrm{L}-\mathrm{B}}=\mathrm{R}_{\mathrm{L}-\mathrm{C}}
$$

Copper loss resistance in the secondary: The copper loss resistance in the secondary is obtained from the results of the short-circuit test and are given by Eq. 20:

$$
\mathrm{R}_{\mathrm{H}-\mathrm{A}}=\frac{\mathrm{K}^{*} \alpha}{3} * \frac{\mathrm{P}_{\mathrm{CC}}}{\left(\mathrm{I}_{\mathrm{CC}}\right)^{2}} * \mathrm{n}^{2}=\mathrm{R}_{\mathrm{H}-\mathrm{B}}=\mathrm{R}_{\mathrm{H}-\mathrm{C}}
$$

From Eq. 20, it is concluded that for both the primary and secondary dispersion resistances, the calculation is performed with the total transformer short-circuit losses $\left(\mathrm{P}_{\mathrm{CC}}\right)$. Additionally, it is assumed that these losses are distributed in $50 \%$ in both the primary and the secondary; for this reason, the $\alpha$ factor is assumed to be 0.5 .

Dispersion inductances: In this case, there is only one element that gathers the total phenomenon of dispersion per phase and is calculated by Eq. 21:

$$
\mathrm{L}_{\mathrm{sh}-\mathrm{A}}=\frac{\mathrm{K}}{2 \pi \mathrm{f}} \sqrt{\left(\frac{\mathrm{V}_{\mathrm{CC}}}{\mathrm{I}_{\mathrm{CC}}}\right)^{2}-\left(\frac{\mathrm{P}_{\mathrm{CC}}}{3\left(\mathrm{I}_{\mathrm{CC}}\right)^{2}}\right)^{2}}=\mathrm{L}_{\mathrm{sh}-\mathrm{B}}=\mathrm{L}_{\mathrm{sh}-\mathrm{C}}
$$

Where:

$\mathrm{V}_{\mathrm{CC}}$ and $\mathrm{I}_{\mathrm{CC}}$ : Correspond to the voltage and short-circuit current of the transformer

f $\quad$ : The applied frequency of the test $(60 \mathrm{~Hz})$

Iron loss resistance: The iron loss resistance is calculated by Eq. 22-24 for each of the phases:

$$
\begin{aligned}
& \mathrm{R}_{\mathrm{m}-\mathrm{a}}=\frac{\mathrm{k}_{\mathrm{C}}}{3} * \frac{\left(\mathrm{V}_{\text {prim }}\right)^{2}}{0.375 * \mathrm{P}_{0}} \\
& \mathrm{R}_{\mathrm{m}-\mathrm{b}}=\frac{\mathrm{k}_{\mathrm{C}}}{3} * \frac{\left(\mathrm{V}_{\text {prim }}\right)^{2}}{0.25 * \mathrm{P}_{0}} \\
& \mathrm{P}_{\mathrm{m}-\mathrm{a}}=\frac{\mathrm{k}_{\mathrm{C}}}{3} * \frac{\left(\mathrm{V}_{\text {prim }}\right)^{2}}{0.375 * \mathrm{P}_{0}}
\end{aligned}
$$

Note that in this case $\mathrm{P}_{0}$ corresponds to the total vacuum losses of the transformer and a distribution of the same of $25 \%$ in the central column and $70 \%$ in the lateral columns is assumed.

Core magnetization inductance: The core magnetization inductance is obtained for each of the phases by Eq. 25-27:

$$
\begin{aligned}
& \mathrm{L}_{\mathrm{m}-\mathrm{a}}=\frac{\mathrm{k}_{\mathrm{C}}}{3 * 2 \pi \mathrm{f}} * \frac{\left(\mathrm{V}_{\text {prim }}\right)^{2}}{0.375 * \mathrm{Q}_{0-\mathrm{a}}} \\
& \mathrm{L}_{\mathrm{m}-\mathrm{b}}=\frac{\mathrm{k}_{\mathrm{c}}}{3 * 2 \pi \mathrm{f}} * \frac{\left(\mathrm{V}_{\text {prim }}\right)^{2}}{0.25 * \mathrm{Q}_{0-\mathrm{b}}} \\
& \mathrm{L}_{\mathrm{m}-\mathrm{a}}=\frac{\mathrm{k}_{\mathrm{C}}}{3 * 2 \pi \mathrm{f}} * \frac{\left(\mathrm{V}_{\text {prim }}\right)^{2}}{0.375 * \mathrm{Q}_{0-\mathrm{c}}}
\end{aligned}
$$

Where:

$\mathrm{Q}_{\mathrm{o}}$ : Corresponds to the total reactive power and a loss distribution is made similar to the previous case

$\mathrm{Q}_{0}$ : Obtained from Eq. 28

$$
\mathrm{Q}_{0}=\sqrt{\left(\frac{\mathrm{V}_{\text {prim }} * \mathrm{I}_{\mathrm{o}}}{3}\right)^{2}-\left(\mathrm{P}_{0}\right)^{2}}
$$

where, $\mathrm{I}_{\text {of }}$ and $\mathrm{P}_{\text {of }}$ are the vacuum currents and the vacuum losses of each of the phases, respectively.

From the parameters and procedures presented, a complete characterization of the elements that compose the test circuit is obtained whose joint implementation allows to simulate and to obtain the frequency response of the induced voltage test. 
Simulation test of the induced stress test: The phenomenon of electrical resonance presents itself as a scenario where the inductive and capacitive reactance of an electric circuit are suppressed by the effects of reaching a characteristic frequency known as resonance frequency. When an electrical circuit reaches resonance, a fully resistive impedance is present which causes a maximum amplitude response at the voltage. In the induced voltage test, frequency variations are presented during the execution of the test where eventually, the elimination of the characteristic inductances of the generator and of the transformers with the capacitances of their respective insulations are eliminated.

After having an electric circuit RLC from the procedures discussed in the previous section, we proceed to obtain the frequency response of the circuit whose ultimate objective is to identify the resonance frequencies of the system. For this purpose, the ATPDraw transient analysis software is used which allows frequency sweeps with very small sampling frequencies which favors the estimation of resonance states (Hoidalen et al., 2009, Pedra et al., 2004).

In the general test circuit, the individual models of each of the elements are coupled to each other considering the connection groups of both the auxiliary and the power transformers. In general, a three-phase RLC circuit with vacuum energization of the transformer under test is used with the conditions to evaluate low frequency transient phenomena such as those associated with resonance and ferroresonance phenomena.

\section{RESULTS AND DISCUSSION}

As a test case, the technical, the characterization, and the simulation procedures presented to a test system composed of the following elements is performed.

- Three-phase synchronous generator: $2560 \mathrm{kVA}, 450$ 720 V, 2053 A, 60-120 Hz, 900-1800 rpm

- Three-phase auxiliary transformer: 500 kVA, Dyn5, 440/34500 V, BIL 200 kV, ONAN

- Three-phase power transformer: 22.5/30 MVA OA /FA, $12 / 115 \mathrm{kV}, 60 \mathrm{~Hz}$

Each of these elements were tested for vacuum, short-circuit, capacitive coupling tests whose data allowed to characterize the RLC parameters.

By performing the simulation of the frequency response of the circuit, the curve shown in Fig. 8 was obtained.

In Fig. 8, the resonance frequency is identified at approximately $552 \mathrm{~Hz}$, at which point a maximum amplitude voltage response is obtained which reaches a value of up to $4.5 \mathrm{kV}$ for each ampere in the circuit feed.

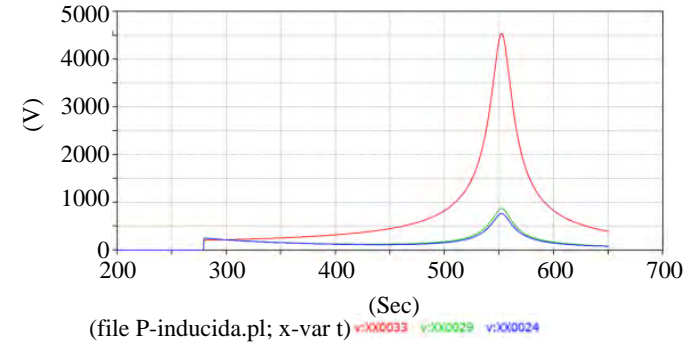

Fig. 8: Frequency response curve-case study I

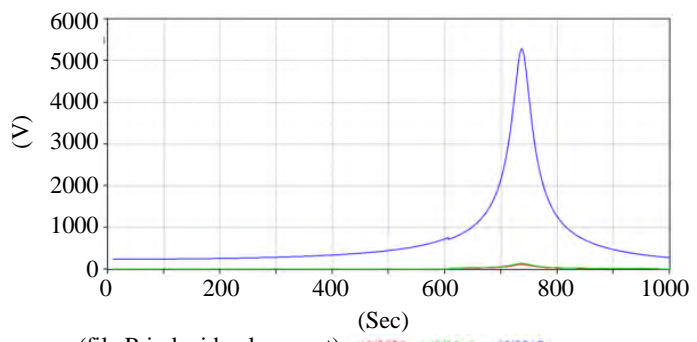

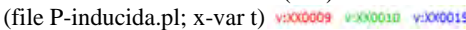

Fig. 9: Frequency response curve-case study II

The obtained resonance frequency for the case study allows to establish the test criterion which ensures the non-presence of voltage elevations due to phenomena such as resonance at values close to $120 \mathrm{~Hz}$ which suggests performing the induced voltage test induced at frequencies close to this one. Also, it is established that the frequency of $552 \mathrm{~Hz}$ should be avoided for the implementation of the test.

Another of the tests performed corresponds to the generator and the transformer of the same previous characteristics but with a power transformer with the following features: Three-phase power transformer: $36 / 60$ MVA OA/FA, 13.8/110 kV, $60 \mathrm{~Hz}$. After the respective modeling and simulation, the frequency response shown in Fig. 9 was obtained.

In this case, according to Fig. 9, it is observed that the resonance frequency corresponds to approximately $737 \mathrm{~Hz}$, at which point a maximum voltage amplitude response is obtained which reaches a value of up to $5.3 \mathrm{kV}$ for each ampere in the circuit feed. Thus, we conclude that the $120 \mathrm{~Hz}$ test criterion is adequate. Furthermore, it is established that the frequency of $737 \mathrm{~Hz}$ should be avoided for the implementation of the test.

The obtained model of induced voltage test facilitates its attainment because it allows the estimation of core parameters, windings and insulation only from the electrical vacuum tests and short-circuit and capacitive coupling measurement. Generally, the performed test cycle to a power transformer starts with the routine vacuum and short-circuit test and ends with the induced 
voltage test. In this way, it is possible to obtain the model at the beginning of the test cycle and therefore, it is possible to have a test criterion at the time of executing the induced voltage test from the results obtained in simulation.

However, it is possible to include more important elements in the model to improve its accuracy such as the phenomena associated with the tertiary winding of the transformer, the non-linear characteristic of the magnetizing branch of the transformer circuits and the generator excitation circuit. Moreover, it is necessary to implement a parameter calculation interface from the test results to facilitate the estimation process and simulation of the test. These topics will be the object of future worksto consolidate a complete test model of easy implementation and simulation.

\section{CONCLUSION}

In operational terms, the model and the simulation of the induced voltage test constitute a useful tool for the laboratory engineer to execute the cycle of tests in the transformer in a safe way for the people as well as for the equipment and the machines which minimizes the risk scenarios and contributes to the implementation of good industrial practices.

The proposed model includes a considerable amount of electrical and magnetic phenomena presented in the normal operation and under test of a transformer, emphasizing the phenomena of vacuum magnetization and the capacitances characteristic of each component. This favors the accurate obtaining of the resonance frequencies of each test circuit.

\section{ACKNOWLEDGEMENTS}

The researchers thank the Industrias ExplorerIngeniería S.A.S company for the support and financing during the development of the project.

\section{REFERENCES}

Barakat, A., S. Tnani, G. Champenois and E. Mouni, 2011. A new approach for synchronous generator terminal voltage control-comparison with a standard industrial controller. Electr. Power Syst. Res., 81: 1592-1601.

Chen, X. and S.S. Venkata, 1997. A three-phase three-winding core-type transformer model for low-frequency transient studies. IEEE. Trans. Power Delivery, 12: 775-782.

Coultes, M.E. and W. Watson, 1981. Synchronous machine models by standstill frequency response tests. IEEE. Trans. Power Apparatus Syst., 100: $1480-1489$.
Despalatovic, M., M. Jadric and B. Terzic, 2011. Modeling of saturated synchronous generator based on steady-state operating data. IEEE. Trans. Ind. Appl., 48: 62-69.

Hadi, S.P. and F.D. Wijaya, 2013. Teaching the large synchronous generator dynamic model under unbalanced steady-state operation. Proceedings of the 2013 International Conference on Information Technology and Electrical Engineering (ICITEE'13), October 7-8, 2013, IEEE, Yogyakarta, Indonesia, pp: 409-413.

Herrera, W., G. Aponte, J. Pleite and C. Gonzalez-Garcia, 2013. A novel methodology for transformer low-frequency model parameters identification. Int. J. Electr. Power Energy Syst., 53: 643-648.

Hoidalen, H.K., B.A. Mork, F. Gonzalez, D. Ishchenko and N. Chiesa, 2009. Implementation and verification of the hybrid transformer model in ATPDraw. Electr. Power Syst. Res., 79: 454-459.

IEEE., 2009. EEE 115: 2009: IEEE Guide for Test Procedures for Synchronous Machines Part 1: Acceptance and Performance Testing Part 2; Test Procedures and Parameter Determination for Dynamic Analysis. Institute of Electrical and Electronics Engineers, Piscataway, New Jersey, USA., ISBN: 9780738161358, Pages: 207.

IEEE., 2010. C57.12.00-2010-IEEE standard for general requirements for liquid-immersed distribution, power and regulating transformers. Institute of Electrical and Electronics Engineers, Piscataway, New Jersey, USA. https://ieeexplore. ieee.org/document/5575268/definitions

Kaniewski, J., 2011. Modeling and analysis of three-phase hybrid transformer using buck-boost MRC. Proceedings of the 2011 7th International Conference-Workshop on Compatibility and Power Electronics (CPE'11), June 1-3, 2011, IEEE, Tallinn, Estonia, pp: 202-207.

Martinez, J.A. and B.A. Mork, 2005. Transformer modeling for low-and mid-frequency transients-a review. IEEE. Trans. Power Delivery, 20: 1625-1632.

Martinez-Velasco, J.A., 2009. Power System Transients: Parameter Determination. CRC Press, Boca Raton, Florida, USA., ISBN: 9781420065299, Pages: 644.

McDermid, W., 2016. Tests on $550 \mathrm{kV}$ inductive voltage transformers. Proceedings of the 2016 IEEE International Conference on Electrical Insulation (EIC’16), June 19-22, 2016, IEEE, Montreal, Canada, pp: 241-242.

Mitchell, S.D. and G.H. Oliveira, 2012. A hybrid modelling methodology for analysing the effect of system transients within power transformers. Proceedings of the 2012 22nd Australasian Conference on Universities Power Engineering (AUPEC'12), September 26-29, 2012, IEEE, Bali, Indonesia, pp: 1-6. 
Mohseni, H., A.S. Akmal, J. Jadidian, E. Hashemi and E. Agheb et al., 2008. Induced voltage test of distribution transformers using static frequency inverters. Proceedings of the 2008 IEEE/PES International Conference and Exposition on Transmission and Distribution, April 21-24, 2008, IEEE, Chicago, Illinois, USA., pp: 1-5.

Mork, B.A., F. Gonzalez, D. Ishchenko, D.L. Stuehm and J. Mitra, 2006a. Hybrid transformer model for transient simulation-part I: Development and parameters. IEEE. Trans. Power Delivery, 22: 248-255.

Mork, B.A., F. Gonzalez, D. Ishchenko, D.L. Stuehm and J. Mitra, 2006b. Hybrid transformer model for transient simulation-part II: Laboratory measurements and benchmarking. IEEE. Trans. Power Delivery, 22: 256-262.
Moses, P.S., M.A. Masoum and H.A. Toliyat, 2010. Dynamic modeling of three-phase asymmetric power transformers with magnetic hysteresis: No-load and inrush conditions. IEEE Trans. Energy Convers., 25: 10401047.

Pedra, J., L. Sainz, F. Corcoles, R. Lopez and M. Salichs, 2004. PSPICE computer model of a nonlinear three-phase three-legged transformer. IEEE. Trans. Power Delivery, 19: 200-207.

Sylvain, C., C. Jerome, B. Jurgen, A. Davide, V. Philippe and B. Sebastian, 2015. Evaluation of insulation systems for the optimal design of high voltage pulse transformers (No. CERN-ACC-2015-0005). CERN, Europe. http://cds.cern.ch/record/1981565 